\title{
LA ENSEÑANZA DEL DIBUJO ENTRE LA ORIENTACIÓN UTILITARIA Y PATRIÓTICA EN LA ESCOLARIDAD ELEMENTAL ARGENTINA (1904-1910)
}

\begin{abstract}
The teaching of drawing between utilitarian and patriotic orientation in Argentinean elementary school (1904-1910)
\end{abstract}

\section{Patricia Andrea Dosio ${ }^{\alpha}$}

Fecha de recepción: 28/08/2019 • Fecha de aceptación: 29/01/2020

Resumen. En este trabajo se estudia la concepción del dibujo en la escolaridad elemental pública argentina bajo el régimen político del período, su relación tanto con las tendencias previas fundadas en la educación para el trabajo y la homogeneización cultural como con la orientación patriótica que se le dio a la enseñanza en general durante la etapa cercana a los festejos por el Centenario de la Revolución de Mayo. Asimismo, se indaga su apropiación de las corrientes pedagógicas en circulación y su particular interés por la psicología experimental e infantil en pedagogía. Luego, se revisan sus aportes en tensión con la política escolar bajo la administración de José Ramos Mejía al frente del Consejo Nacional de Educación, orientada a la formación del sentimiento patriótico en la población infantil y sus nuevas iniciativas en enseñanza artística.

Palabras clave: Dibujo; Enseñanza artística; Martín Malharro; Nacionalismo; Trabajo.

Abstract. In this paper we study the conception of drawing in public elementary school in Argentina and its relationship with the previous orientation based on education for work and cultural homogenization. We also explore its connections with the patriotic trend towards education in general upon approaching the celebrations for the Centennial of the May Revolution. Likewise, we examine the discipline's appropriation of pedagogical currents in

\footnotetext{
${ }^{\alpha}$ Licenciatura en Filosofía, UntrefVirtual, Universidad Nacional de Tres de Febrero. Av. San Martín 2024 - B1678GPW. Caseros. Provincia. de Buenos Aires. Argentina. pdosio@palermo.edu (DD https:// orcid.org/0000-0003-4559-0211
}

Cómo citar este artículo: Dosio, Patricia Andrea. «La enseñanza del dibujo entre la orientación utilitaria y patriótica en la escolaridad elemental argentina (1904-1910)». Historia y Memoria de la Educación 12 (2020): 433-462 
circulation at the time and its particular interest in experimental psychology and pedagogy. Finally, we review its contribution and resulting tension with school policy under the administration of José Ramos Mejía at the head of the National Council of Education, which sought to form patriotic sentiment in the youth population and adopt new initiatives in artistic education.

Keywords: Drawing; Artistic education; Martin Malharro; Nationalism; Working.

\section{INTRODUCCIÓN}

La configuración de la enseñanza artística como disciplina escolar jugó un rol específico en el marco del régimen político argentino. La incorporación del dibujo como materia en el plan de estudios de nivel primario constituyó un instrumento que acompañó la búsqueda de homogeneización cultural frente a la cuestión inmigratoria y aportó en la conformación del ciudadano como parte de los saberes que los niños debían aprender para desempeñarse en la sociedad civil y el sistema político. Como sostiene Ricardo Bottarini, ${ }^{1}$ la Ley 1420 estableció el nivel primario como común y «con el doble objetivo de nacionalizar a la masa de inmigrantes que arribaba a nuestro país y, concurrentemente, formar al ciudadano». ${ }^{2}$ Desde esta perspectiva, sus contenidos contribuirían a la socialización de los niños inmigrantes y nativos en los valores nacionales. Aparte, el acceso que su aprendizaje suponía a los saberes socialmente productivos significaba una preparación para los jóvenes como mano de obra de pequeños talleres y fábricas. ${ }^{3}$

Sin embargo, al comenzar el siglo veinte, en consonancia con líneas de pensamiento que influyeron en la conformación de la educación artística estadounidense y europea, tuvo lugar una revisión y transformación

\footnotetext{
${ }^{1}$ Ricardo Bottarini, «Leer, escribir, votar: la conflictiva definición del curriculum ciudadano», en Para una historia de la enseñanza de la lectura y la escritura en la Argentina: del catecismo colonial a La Razón de Mi Vida, dirs. Héctor Cucuzza y Pablo Pineau (Buenos Aires: Miño y Dávila Editores, 2002), 77-105.

2 Bottarini, «Leer, escribir, votar: la conflictiva definición del curriculum ciudadano», 79.

${ }^{3}$ Los saberes socialmente productivos son aquellos «volcados a la praxis laboral, convivencial, organizativa, recreativa, y de variados registros surgidos de las relaciones sociales y económicas locales, barriales y regionales» en dirs. Adriana Puiggrós y Rafael Gagliano, La fábrica del conocimiento: los saberes socialmente productivos en América Latina (Rosario: Homo Sapiens, 2004$), 25$.
} 
de los objetivos iniciales de la materia en conexión además con cambios pedagógicos y políticos locales. En este sentido, el artículo se detiene en el análisis de tales modificaciones bajo diferentes gestiones y a la luz de las propuestas nacionalistas. Primeramente, se indaga la labor renovadora y crítica de la tradición en enseñanza artística encarada por el artista plástico Martín Malharro y sus divergencias con la postura del doctor José María Ramos Mejía, desarrollada en otro apartado. Por último, el derrotero de la asignatura Dibujo es explorado a través de las tensiones entre lo nacional y lo laboral; entre la estética y el higienismo.

\section{REVISIONES Y NUEVAS PROPUESTAS. LA LABOR DE MARTÍN MALHARRO}

En 1904 una nueva administración educativa comenzó a otorgarle otro espacio a la enseñanza del dibujo en la escuela elemental. Al frente de la presidencia del Consejo Nacional de Educación fue designado Ponciano Vivanco (1865-1929), mientras que el educador Pablo Pizzurno (1865-1940) fue nombrado Inspector Técnico General. Ambos compartían una postura nacionalista, aunque distante del extremismo que eclosionaría en años posteriores con la asunción de José María Ramos Mejía. ${ }^{4}$ Pizzurno también se separaba de las posiciones tendientes a la militarización de la escuela, en incremento por esos años. Así lo dio a entender, al decir que la obra iniciada por los hombres de la Revolución de Mayo se debía continuar menos en el campo de batalla que «en el campo del trabajo que fecunda la tierra, hace andar a las máquinas de la industria, activa el comercio que enriquece, civiliza las masas con la educación».5 Asimismo, sostenía que cada trabajador, sea el agricultor, el

\footnotetext{
${ }^{4}$ Sobre las gestiones de Vivanco y Pizzurno, ver: Adriana Puiggrós y Sandra Carli, Sociedad civil y estado en los orígenes del sistema educativo argentino (Buenos Aires: Galerna, 1991). Sobre la materia Dibujo en etapas previas, ver: Patricia Andrea Dosio, «Aprender a dibujar los contornos del país: Vínculos entre la enseñanza del dibujo escolar y los conocimientos geográficos en el Buenos Aires finisecular (1880-1900)», Caderno de Geografía 24, no. 2 (2014): 90-104; https://www.aacademica.org/patricia.andrea.dosio/9 (consultado el 10-5-2018). Patricia Andrea Dosio, «Entre el atelier, la escuela y la fábrica: La Sociedad Estímulo de Bellas Artes y la capacitación de mano de obra urbana en el Buenos Aires decimonónico», Reflexión Académica en Diseño y Comunicación 25, no. 23 (2014), 93-99.

${ }_{5}^{5}$ Pablo Pizzurno "Consejos a los maestros: cómo se forma el ciudadano», El Monitor de la Educación Común 26, no. 404 (31 de agosto, 1906): 106.
} 
obrero, el hombre del bufete, con su labor «producen también benéficas revoluciones en las artes, en las industrias, en el comercio, en las ciencias, en la organización pública» y aseguran independencias ${ }^{6}$.

En ese marco, Martín Malharro (1865-1911) inauguraba su obra educativa a escala nacional. Como artista plástico, Malharro se formó inicialmente en los cursos de la Sociedad Estímulo de Bellas Artes de Buenos Aires. Pero pronto manifestaría su rechazo a los parámetros clásicos y académicos encarando su búsqueda personal en la renovación del arte local. A su regreso de Europa, explicitó la necesidad de crear un arte de cuño nacional fundado en una modalidad diferente a la académica, que en el plano educativo mantenía una enseñanza basada en el modelo vivo y la copia de estampas y calcos. Estaba convencido de que la formación de los artistas debía partir de la observación directa de la propia naturaleza. Partiendo de las tendencias dominantes en la época de su estadía europea, como el realismo, simbolismo y postimpresionismo e imbuido del ideario anarquista, elaboró una concepción estética propia y original de lo que debía ser el desarrollo del arte argentino.

Se incorporó a la estructura del Consejo Nacional de Educación a través de un encargo de Vivanco para la decoración mural del salón de fiestas de la Escuela Presidente Roca de Buenos Aires. Era además un momento donde empezó a priorizarse la transformación de la enseñanza en general y del dibujo en particular, a fin de producir pedagógicamente en el niño un sentido estético y moral. De esta manera, Malharro no fue el único que propuso un cambio en la enseñanza del dibujo. Es más, no se trató de una transformación apoyada por decisiones individuales o vinculadas a un proyecto político determinado, sino de un movimiento pedagógico a un grado mundial. En el Congreso Internacional de Enseñanza del Dibujo en Berna (1904) se planteó la necesidad de una transformación en su enseñanza, bregando por una concepción moderna que suponía una mayor inclusión social. Esta inclusión favorecería el reconocimiento del carácter indispensable del aprendizaje artístico,

6 Pizzurno, «Consejos a los maestros: cómo se forma el ciudadano», 107-109. 
trascendiendo las ventajas clásicas atribuidas a su aprehensión, esto es, el goce estético, la producción artística y utilitaria: es tiempo, se decía, «de encarar el dibujo de otro modo que á través del placer que da al dilettante, la obra de arte que pueda ofrecer al artista, ó el servicio industrial que presta al obrero». En efecto, la concepción propiciada por el congreso sostenía que «se aprende el dibujo para saber ver, luego para representar ó trazar operando con las formas suministradas por el mundo visible». ${ }^{7}$ Se alegaba la necesidad de un nuevo enfoque menos reduccionista. En las escuelas públicas estadounidenses, paradigmas educativos para muchos, también operaron cambios didácticos y conceptuales. Si bien se admitió la importancia que revistió en su momento la adopción de la copia del natural, también se consideró que «tal principio no basta para dar consistencia á un sistema». ${ }^{8}$ Además, se apeló, del mismo modo que en el congreso suizo, a la instauración de un concepto moderno del dibujo, adicionando las contribuciones de las nuevas corrientes pedagógicas que abogaban por la expresión libre del niño en su apresto para la vida:

Las antiguas concepciones del dibujo puramente educativo ó puramente industrial, se han ensanchado poco á poco para abarcar al presente tres grandes puntos de vista que corresponden á tres grandes necesidades á las cuales debe la escuela dar plena satisfacción si ha de llenar su programa de 'escuela para la vida'.

Es un hecho que ningún maestro puede desconocer, la necesidad que el niño siente de expresar en una forma tangible, más expresiva que las palabras, los pensamientos ó las emociones que lo ocupan. [...] El dibujo es ante todo expresión en las escuelas norteamericanas. ${ }^{9}$

Esta tendencia fue una de las tantas líneas de pensamiento que influyeron en la conformación de la educación artística en Argentina como

\footnotetext{
7 «El Congreso Internacional de la enseñanza del Dibujo en Berna», El Monitor de la Educación Común 25, no. 388 (31 de mayo, 1905): 845.

${ }^{8}$ Ernestina López, «La enseñanza del dibujo en las escuelas primarias de los Estados Unidos», El Monitor de la Educación Común 25, no. 390 (31 de julio, 1905): 985.

9 Ernesto Nelson, «Desde Norteamérica», El Monitor de la Educación Común 25, no. 391 (31 de agosto 1905): 60 .
} 
en Estados Unidos y Europa. Las justificaciones de atisbos utilitarios, mientras iban cediendo paso, se entrecruzaban en el camino con concepciones románticas e idealistas que enfatizaban «el valor de la educación moral; las vinculaciones entre el arte, la naturaleza y la experiencia espiritual; la importancia del arte como estudio cultural; y el rol de la imaginación y el genio en el arte». ${ }^{10}$

Iniciado el siglo veinte y en consonancia con los desarrollos internacionales, comenzaron a expresarse voces que vindicaban por un desplazamiento de la aplicación industrial en los contenidos del dibujo escolar, aplicación que se había enarbolado previamente como una de las principales funciones de su enseñanza. En paralelo, tuvo lugar el establecimiento a nivel post-primario, aunque limitado, de escuelas de artes y oficios y de vertiente técnica para cubrir este deslizamiento, conforme al crecimiento industrial. Esta transformación en los fines de la enseñanza del dibujo en la escolaridad común se asoció a las modificaciones en los métodos didácticos de raíz académica. Es que el dibujo como se venía enseñando «torturando facultades preciosas de los niños, restringiendo con violencia» la expresión individual, «sin tener en cuenta para nada sus impresiones, subordinando todos los principios naturales y las ventajas de la enseñanza á trazados geométricos, á retratos de prohombres, copia fiel de estampas» ${ }^{11}$ no había redundado favorablemente. Estos reclamos se vieron sostenidos por las aportaciones froebelianas que rescataban la autonomía de la mente y por ende la introducción de actividades y empleo de distintos materiales que estimularan el desarrollo mental, así como el principio del juego y el descubrimiento. En esta nueva batida se ubicó la labor de Malharro.

Uno de los aspectos en que focalizó su atención fue la diferenciación entre los objetivos y prácticas del dibujo en la instrucción primaria y en la orientación industrial: «las prácticas e ideales de la escuela especial de arte ó industrias tiene poco radio de acción en la escuela primaria en

\footnotetext{
10 Manuel Salas y Emilia Troller, «El dibujo en la escuela primaria», El Monitor de la Educación Común 25, no. 391 (31 de julio, 1905):1055-1056.

11 Salas y Troller, «El dibujo en la escuela primaria», 1056.
} 
la que los fines y elementos difieren fundamentalmente».12 Malharro afirmaba que la enseñanza del dibujo hasta ese momento no contaba con un principio pedagógico definido y respondía a métodos basados en el uso de la cuadrícula, la copia de estampas y el estudio de figuras geométricas. Adaptaciones incompletas de programas franceses de corte académico y racionalista sin tener en cuenta las características y necesidades de las escuelas locales. Su método de enseñanza, por el contrario, se basó en la copia del natural e incorporó el dibujo libre y la consideración de la capacidad innata del niño, partiendo de su reinterpretación de los escritos de pedagogos en boga. Malharro exhibió un amplio saber crítico de diferentes propuestas pedagógicas. En su publicación de 1911 da cuenta de los métodos de Pestalozzi, Ramsauer, Froebel. Destaca a Peter Schmid, introductor en 1825 del trabajo del natural en lugar de la copia de modelos ya dibujados. Estos métodos tenían en común a la geometría como base de la inventiva. También hace mención de Jacotot, Hillard, los métodos Ravaisson y Guillaume. De todos modos, no adhirió a un método en especial: «en esta sucesión larga de evoluciones, de mariposeos de diletantes, artificios de pedagogos y pedagogías de artistas, se perdió para siempre de vista el factor principal: el niño».13 Su propuesta, además de demostrar erudición y apropiación de las corrientes pedagógicas en circulación, profundizaba en el sujeto del aprender. De hecho, se interesó por la psicología experimental e infantil en pedagogía, sobre todo a través de Rodolfo E. Senet ${ }^{14}$. Es posible que este interés estuviera guiado por las críticas a la instrucción pública de entonces efectuadas por Senet y pedagogos como Víctor Mercante. Ambos se distinguieron por una línea del cientificismo naturalista particular en educación y ostentaban apreciaciones diversas al discurso de tendencia spenceriana. ${ }^{15}$ La idea de

\footnotetext{
12 Martín Malharro, «De la contribución del dibujo libre á la enseñanza patriótica», El Monitor de la Educación Común 28, no. 429 (30 de septiembre, 1908): 212.

${ }_{13}$ Martín Malharro, El dibujo en la escuela primaria. Pedagogía-Metodología (Buenos Aires: Cabaut y Cía., 1911), 226.

14 Investigador de la psicología del niño y del adolescente. Profesor de Antropología, de Psicología Anormal y de Psicopedagogía en la Facultad de Ciencias de la Educación de la Universidad Nacional de La Plata y docente de la Escuela Normal de Profesores Mariano Acosta.
}

${ }^{15}$ La cuestión de las líneas filosóficas de orientación positivista es mucho más compleja que una simple adopción de postulados. Ver al respecto Celina Lertora Mendoza, «Recepción de ideas filosóficas. Problemas metodológicos e histórico-críticos de su investigación. Estudio de caso: la filosofía 
clases únicas y programas estereotipados, modelos educativos enciclopédicos y memorísticos, que no consideraban las necesidades de cada sujeto, eran aspectos no aceptados por estos intelectuales. Senet, al igual que Mercante, propiciaba la observación, la experimentación y la afectividad infantil. Apostaba por la importancia del juego en el desarrollo de aptitudes nobles e intelectuales y rechazaba de plano para la salud moral y física del niño que el juego fuera reemplazado por quehaceres laborales. ${ }^{16}$ Entonces, las prácticas lúdicas por encima de las laborales, la experimentación y observación en lugar de métodos memorísticos y repetitivos de copia fueron aspectos que guiaron el juicio controversial de Malharro a la forma de enseñanza de la materia tanto en la educación primaria como secundaria.

En un escrito dedicado al ministro de Instrucción Pública, Juan R. Fernández, y al presidente del Consejo Nacional de Educación, Ponciano Vivanco, Malharro dio a conocer su opinión sobre la inadecuación de los métodos empleados hasta el momento: «quiere el autor de ese trabajo que el actual sistema de aprendizaje del dibujo en los colegios se substituya por otro que preste á los fines mediados alguna preferencia sobre los inmediatos, generalizando y sintetizando hasta su expresión más íntima el mayor número de conocimientos que el dibujo abarca». ${ }^{17} \mathrm{Si}$ bien Malharro reconocía la relevancia del lenguaje visual para la formación profesional, no concordaba con la planificación de la materia hacia estos fines

[...] y sea hombre de ciencia, artistas, comerciante ó simple obrero, el lenguaje de las formas tendrá siempre para él idéntica importancia. Pero para estos fines es necesario que el concepto del dibujo escolar se diferencie del que caracteriza al dibujo de arte ó al dibujo industrial ó de arte aplicado. ${ }^{18}$

\footnotetext{
argentina de 1890 a 1920», Cuadernos del Sur 31-32 (2001): 37-63. http://bibliotecadigital.uns.edu.ar/ scielo.php?script=sci_arttext\&pid=S1668-74342001001100003 (consultado el 10-6-2018).

16 Rodolfo Senet, «Psicología del juego en los niños», Archivos de Psiquiatría, Criminología y Ciencias Afines 11 (1912): 154-155. Rodolfo Senet, "Afectividad y emotividad infantil», El Monitor de la Educación Común 433, no. 28 (31 de enero, 1909): 45-54. María Amalia Torrá, «Organización de las clases», El Monitor de la Educación Común 586, no. 40 (31 de octubre, 1921): 112-123.

17 Martín Malharro, «El dibujo en los colegios nacionales», El Monitor de la Educación Común 24, no. 378 (31 julio, 1904): 1268.

18 Martín Malharro, «Del dibujo libre: á los señores directores de las escuelas comunes de la Capital», El Monitor de la Educación Común 28, no. 428 (31 de agosto, 1908): 54.
} 
Impulsaba así para la enseñanza del dibujo en la escuela una finalidad pedagógica pura y la expresión de la subjetividad del niño. En su concepción, la correlación entre materias era bienvenida, pero entrañaba un tratamiento cuidado y complejo, «cuya solución no puede estar librada á empirismos é improvisaciones en todos los casos discutibles por lo perjudiciales». ${ }^{19}$ A esto agregaba que «si el dibujo puede ser un auxiliar para el estudio de la caligrafía, en cambio la caligrafía no será un auxiliar para el estudio del dibujo». ${ }^{20}$ Estas reflexiones pueden hacerse extensibles a las conexiones de Dibujo con otras materias, como Historia. De acuerdo con su razonamiento, Malharro pretendió significar que la asignatura Dibujo conlleva la comprensión e interpretación por parte del alumno del modelo o del tópico a dibujar, más allá de sus rasgos descriptivos o del modo en que resuelva la representación. En suma, interesaba la expresión singular de cada alumno como individuo. Tampoco se apuntaba al extremo de aceptar, en pro de la libertad e imaginación de los jóvenes, «un soldado de San Martín con la gorra prusiana reglamentaria en nuestro ejército actual», que, a su entender, «sería una mala contribución del dibujo a la historia». Por el contrario, el maestro debía guiar, brindar documentación válida y, en base a ello, tendría lugar «el desenvolvimiento de la imaginación». ${ }^{21}$ El alumno tiene la capacidad de comprender y deducir el tema según su propia óptica.

Su descripción crítica del sistema educativo señalaba que la población escolar, además de representar una significativa fuerza económica, exigía miramientos que fueran más allá de la creación de establecimientos educativos. Afirmó con su peculiar prosa que, al personal docente escasamente preparado, se adicionaba «el maestro sin título»,

recurso supremo al que debía acudirse como medida salvadora, para contrarrestar la ola inmensa, que se presentaba cada vez más creciente y abrumadora, con cifras aplastadoras de analfabetos, de

\footnotetext{
19 Martín Malharro, «Los deberes ilustrados en la Escuela Primaria», El Monitor de la Educación Común 23, no. 405 (31 de agosto, 1906): 122.

20 Martín Malharro, «El dibujo en los grados inferiores de la escuela primaria», El Monitor de la Educación Común 23, no. 387 (30 de abril, 1905): 639.

${ }^{21}$ Malharro, «De la contribución del dibujo libre á la enseñanza patriótica», 217.
} 
año en año reforzadas por la inmigración, en aumento cada vez mayor, la que, al par que representaba una fuerza económica considerable, reclamaba también cuidados en el orden moral é intelectual, preocupación que sólo se afrontaba debidamente con escuelas, escuelas y escuelas, en todos los ámbitos del territorio de la nación, y con maestros que, si no existían, había que inventarlos. ${ }^{22}$

En su alocución se articula el reconocimiento de los altos índices de analfabetismo, sumados a la inmigración, con su evaluación negativa del abordaje de estos problemas por parte de la dirigencia. En especial se cuestionaba la actuación de Ramos Mejía, que se limitaba, según su parecer, a la invención de maestros y la creación indiscriminada de escuelas. Desde su perspectiva, un maestro que encarara la enseñanza del dibujo requería contar con una formación pedagógica y metodológica. Detentar un título de bellas artes era insuficiente si se carecía de un conocimiento sobre la psicología infantil. En esta dirección, estableció cursos temporarios de dibujo para maestros y directivos con el respaldo de Pizzurno.

Por otro lado, Malharro adaptó la asignatura hacia la orientación patriótica de acuerdo con las nuevas exigencias nacionales de la escuela en el Centenario. Destacó que el campo de acción del dibujo respecto a la enseñanza patriótica es ilimitado, rescatando además la importancia del establecimiento de correlaciones entre Historia y Dibujo. También valorizó la intervención del docente en la clase de dibujo libre al tratarse temas históricos, pues el docente deberá «ilustrar á los alumnos sobre dicho punto». Asimismo, afirmó que «las lecciones del pasado se encarnarán en la realidad del presente, surgiendo de esa conjunción la debida lección que será así de Historia, de Moral y de Dibujo». ${ }^{23}$ Su intención de incentivar el trabajo libre del alumno y la expresión de su individualidad la articuló con la educación nacional, tal vez con el fin de aportar otra

\footnotetext{
22 Martín Malharro, «El dibujo y la educación estética en la escuela primaria y en la enseñanza secundaria», Censo General de Educación del 23 de mayo de 1909, ed. Alberto B. Martínez (Buenos Aires: s/e., 1910), 295.
}

${ }_{23}$ Malharro, «De la contribución del dibujo libre á la enseñanza patriótica», 216-217. 
vía a la dirección general que terminó recibiendo la instrucción primaria por entonces.

Malharro señaló que el dibujo libre y el decorativo colaborarían en la enseñanza patriótica mediante composiciones del escudo nacional y los escudos de cada uno de los estados confederados. Además, dijo que «la flora y fauna argentinas pueden también prestar un importante contingente para la concepción de temas ornamentales que adoptarían así un carácter propio». ${ }^{24}$ La idea de inculcar y formar al niño en los valores nacionales a través de un saber sobre lo particular del territorio (fauna, flora, paisajes), a un tiempo que sobre su totalidad (historia, simbología), si bien de un modo diferente, se atisbaban en el proyecto pedagógico nacional y en la nueva gestión del Consejo que asumió en 1908. A su vez, estos aspectos se enrolaban con el pensamiento del evolucionismo biológico. En la Argentina finisecular, la incidencia de la ciencia afianzó el conocimiento de la naturaleza a través de métodos acordes con el racionalismo científico. Este pensamiento se exhibía en el conocer la flora y fauna, en la implementación de salidas escolares y el fomento de la observación directa, así como la promoción del gusto y el sentimiento en tanto necesidades de la vida, cuya satisfacción conducirían a la evolución del niño y de la especie. ${ }^{25}$

Para Malharro el recurso a la historia nacional constituía un medio para incentivar el pensamiento creativo e imaginativo del niño y, a la vez que enlazaba Historia y Dibujo, «se daba una lección indirecta de moral realizando los propósitos del doctor Ramos Mejía en lo que respecta á su ideal». ${ }^{26} \mathrm{El}$ foco de su atención residía en el dibujo como medio de expresión de ideas, sentimientos, sin manipular la espontaneidad ni el desenvolvimiento natural e individual del alumno. En resumen, reclamaba, y este fue el sentido que le diera a su gestión, la no exigencia del niño como adulto — que implicaba la eliminación del

\footnotetext{
${ }^{24}$ Malharro, «De la contribución del dibujo libre á la enseñanza patriótica», 216.

${ }_{25}$ Sobre evolucionismo, Gustavo Vallejo y Marisa Miranda, «Evolución y revolución: explicaciones biológicas de utopías sociales», dirs. Hugo E. Biagini y Arturo A. Roig, El pensamiento alternativo en la Argentina del siglo XX (Buenos Aires: Biblos, 2004), 403-417.

${ }^{26}$ Malharro, «Del dibujo libre: á los señores directores de las escuelas comunes de la Capital», 65.
} 
dibujo técnico u orientado hacia los oficios- y la capacitación pedagógica del maestro, encomiando a la materia como un agente educativo. Otorgaba al dibujo otro status, rescatando sus aristas pedagógicas y más cercanas a lo artístico, a diferencia de la tendencia utilitaria que concebía al dibujo como base para el trabajo o como dimensión de la ciudadanía, al tender a la definición actitudinal.

Tampoco lo seducía la idea de que el dibujo constituyera un instrumento de homogeneización. Fue categórico al sostener que «las leyes universales se verán defraudadas, el mundo se regirá por nuevos principios, obedeciendo sus elementos disciplinados militarmente á la fantasía infantil para la que no hay escrúpulos, vallas, dificultades ni imposibles». ${ }^{27}$

Con claridad, se revela una percepción contraria a la educación primaria como la venía encarando el oficialismo. La presencia de los batallones infantiles, la participación de escolares en actos patrióticos públicos hasta el montaje cívico-militar eran rasgos propios de una escuela pensada como parte del aparato para apuntalar el sentimiento de lo nacional. Se atendió a la enseñanza de la historia patria para que la escuela fuera «eminentemente argentina para el escolar» pues «maestros, libros, mapas é ilustraciones murales, mobiliario, útiles, todo debe estar ungido con el óleo sagrado de la nacionalidad».28

Dentro de esta urdimbre, el dibujo contribuía esgrimiendo un cuerpo conceptual y didáctico particular. Pronto, el carácter que el ideario de Malharro comenzó a darle a la enseñanza del dibujo pareció disgustar al oficialismo, sobre todo bajo la administración de Ramos Mejía. Para el artista, el universo creativo del niño se vería aplacado y cegado en este contexto: "pero pretended subordinar disciplinado incontinenti sus facultades creativas á las perceptivas y estas dos á las figurativas y de un golpe habréis apagado un volcán». ${ }^{29}$ Percibía Malharro al infante menos como ser salvaje y bárbaro a adiestrar, que como sujeto espiritual.

\footnotetext{
${ }^{27}$ Malharro, «De la contribución del dibujo libre á la enseñanza patriótica», 204.

28 «Educación patriótica», La Prensa, 15 de mayo, 1893.

29 Malharro, «De la contribución del dibujo libre á la enseñanza patriótica», 204.
} 
Auspiciaba la educación del niño a través de lo lúdico y su diferenciación del mundo adulto.

\section{DIBUJO EN EL PROGRAMA PATRIÓTICO DE RAMOS MEJÍA}

Iniciado el siglo veinte, la currícula elemental se vio invadida por ansias holísticas, impronta que cooperó con la formación nacional de los niños como futuros ciudadanos argentinos. A esta nueva planificación de carácter integral y convergente se adecuó la materia Dibujo. A la par de las otras disciplinas, ejercicios, trabajos escolares y ejemplos brindados a los párvulos, de Dibujo se generaron derivaciones hacia la educación de hábitos morales, base del bienestar del individuo y de la comunidad. Así lo definía Pablo Pizzurno al afirmar que «no sólo la Historia y la Geografía y la Lectura y la Composición, sino la Caligrafía y el Trabajo manual y el Dibujo, el Ejercicio físico y la Música y hasta el cuidado y el modo de corregir los cuadernos de deberes, pueden motivar lecciones morales fructíferas». ${ }^{30}$ Este discurso se encuadraba dentro del proyecto mayor de tono patriótico que, en definitiva, reorientaba el valor de la enseñanza del dibujo. Por ejemplo, un colaborador de El Monitor sostenía que «el valor educativo de la enseñanza artística es tal, que concurre de la manera más eficaz á la formación moral del ciudadano y al desarrollo integral de sus facultades».31

En vísperas del Primer Centenario, el Consejo Nacional de Educación estaba empeñado en la consecución de un programa «de gran trascendencia para la educación de la niñez: la enseñanza cívica y patriótica, orientada sanamente en el sentido de robustecer el espíritu nacional», abarcando el respeto a la tradición, el culto de sus glorias, próceres y por el «desarrollo de todos los sentimientos que mayormente despiertan, avivan y arraigan el amor á la patria hasta convertirlo en deber y en capacidad de abnegación y sacrificios».32 A lo largo del período fue gradualmente

\footnotetext{
30 Pizzurno, «Consejos a los maestros: cómo se forma el ciudadano», 110.

${ }^{31}$ Luis Frumento, «La nueva orientación pedagógica en la enseñanza elemental y secundaria», El Monitor de la Educación Común 28, no. 404 (31 de agosto, 1909): 316.

32 José Zubiaur, «Discurso», El Monitor de la Educación Común 29, no. 454 (31 de octubre de 1910): 147.
} 
acentuándose la postura argentinizante como prolegómeno de los festejos. En el sentido de una educación patriótica, aunada a la promoción de la educación masiva, se desarrolló una política de reorganización de los programas nacionales en los establecimientos públicos. Estos planes ponderaban una instrucción centrada en una determinada perspectiva de la historia patria. Como parte de esta política, se llevó a cabo el nombramiento de figuras que compartían ideales de corte nacionalista. Empero, la designación de José Ramos Mejía al frente del Consejo Nacional de Educación significó en la escuela primaria la imposición de una auténtica liturgia cívica. ${ }^{33}$ Como intelectual y hombre de ciencia, Ramos Mejía desempeñó una múltiple actividad, a la par que desarrolló una percepción de la multitud como masa a instruir. ${ }^{34}$ Con estos presupuestos, apuntaló la política escolar destinada a la formación del sentimiento patriótico en la población infantil: «creyó útil fundar escuelas y las fundó a millares; anheló transfundir el sentimiento de la argentinidad en la enseñanza y ejecutó su programa de educación nacionalista». ${ }^{35}$ La transmisión de la historia de la nación y la identificación con los héroes nacionales fueron modelos a los que se apeló como estrategia para la formación de los niños. En consonancia con esta política, se buscó el emparejamiento social y cultural frente a la inmigración y el cosmopolitismo, percibido como destructores del ser nacional, y se intentó combatir el avance del anarquismo. ${ }^{36} \mathrm{Al}$ año siguiente de asumir la presidencia del Consejo Nacional de Educación, sucediendo a Ponciano Vivanco, Ramos Mejía presentó para aprobación del Consejo un conjunto de iniciativas publicadas como La Escuela Argentina en el Centenario. Entre las directivas propuestas, Ramos Mejía instó la revisión de los planes en

\footnotetext{
${ }_{33}$ Tulio Halperin Donghi, El espejo de la historia. Problemas argentinos y perspectivas latinoamericanas (Buenos Aires: Sudamericana, 1987), 226.

${ }^{34}$ Impulsor de la doctrina positivista en el Círculo Médico desde sus tiempos de estudiante, José Ramos Mejía fue funcionario y maestro, con un marcado apego por la historia como disciplina. Sus interpretaciones sobre las multitudes argentinas se convirtieron en referentes ideológicos de la clase dirigente.

35 José Ingenieros, «La obra intelectual de J. M. Ramos Mejía», El Monitor de la Educación Común 33, no. 509 (31 de mayo, 1915): 290.

36 Sandra Carli, Niños, pedagogía y política. Transformaciones de los discursos acerca de la infancia en la historia de la educación argentina entre 1880 y 1955 (Buenos Aires: Universidad de Buenos Aires/ Miño y Dávila, 2002), 228-229.
} 
curso de las escuelas primarias para abonar la orientación nacionalista de la educación popular.

En este contexto, por expresa disposición del presidente del Consejo, Pizzurno confeccionó un nuevo programa con una notoria orientación hacia la enseñanza patriótica. Sostuvo, en lo que respecta a Dibujo, que este ramo puede indirectamente prestar su concurso a la educación patriótica. Para fundamentarlo, citó párrafos de un informe que había extendido Malharro en su función de inspector y que condensaban sus propósitos al incluir el dibujo libre y de inventiva, visitas al Museo Histórico y la realización de «temas de carácter nuestro, no solo en lo que representa lo visto por el niño, sino también en lo que significaría la expresión de sus sentimientos desde el punto de vista de la historia nacional ${ }^{37}$. Se incitaba aquí a la subjetividad del infante y su propia lectura de la historia. No obstante, esta propuesta debe haber resultado inapropiada al nuevo presidente del Consejo para la consecución de su proyecto nacionalista y de ritualización de la cultura escolar. De allí que encarara una reformulación de los mismos sin la participación de Pizzurno. Este desplante condujo a su dimisión a la que siguió la de Malharro y el nombramiento del Inspector General de Provincias, Ernesto Bavio, como Inspector Técnico General. ${ }^{38}$ Ya desde su gestión en Entre Ríos, Bavio había demostrado férrea perseverancia por la instauración del nacionalismo en educación, poniendo en práctica conceptos de enseñanza patriótica y polemizando con las escuelas extranjeras, especialmente rusas y hebreas. El pensamiento de Bavio era coincidente con el ideario de Ramos Mejía, quien había expresado cómo la excesiva extensión de Dibujo, Música, Trabajo Manual y Ejercicios Físicos restaban atención a la Lectura, Escritura, Aritmética, Lenguaje y Ejercicios Intuitivos. ${ }^{39}$ Sin embargo, aclaró que no buscaba su exclusión, sino su aprovechamiento «como materias concurrentes y no

\footnotetext{
37 Pablo Pizzurno, «La educación patriótica. Informe del Inspector técnico general», El Monitor de la Educación Común 28, no. 425 (31 de mayo, 1908): 350.

38 Patricia Artundo, «Bibliografía crítica de Martín A. Malharro: el dibujo como agente de educación», Boletín del Instituto de Teoría e Historia del Arte Julio E. Payró 9 (2003):73-108.

39 José Ramos Mejía, Primer Informe presentado al Ministerio de Justicia é Instrucción Pública de la Nación por el Presidente del Consejo Nacional de Educación, Dr. José María Ramos Mejía (Buenos Aires: s.e., 1908), 13-14.
} 
absorbentes».40 Pese a que la voluntad de Ramos Mejía parecía propender el desinterés por la enseñanza artística en la primaria, las acciones llevadas a cabo bajo su administración evidencian un viraje más que una desaprobación y desidia acerca del rol que debían cumplir. Esta nueva etapa puede vislumbrarse tanto en la creación de una Oficina de Ilustraciones y Decorado Escolar como en los informes que fueron solicitados a distintas personalidades del arte de entonces ${ }^{41}$.

La Oficina de Ilustraciones y Decorado Escolar respondía a la «sentida necesidad de someter el decorado de nuestras escuelas, hasta la fecha librada á la buena voluntad del maestro, á un plan de cultura estética». Un plan acorde con «nuestros progresos educacionales y que tienda á difundir el buen gusto y propagar el conocimiento de las bellas artes», aunado al conocimiento de los paisajes nacionales «las bellezas de nuestra tierra»y de los héroes patrios «hombres que, en una ú otra forma, han contribuido á su independencia, cultura y progreso».42 Con la creación de esta nueva dependencia, que aportaría además al desarrollo de la cultura estética, se lograría contribuir de modo eficaz «á un porvenir más dichoso, colocando á las generaciones nuevas en un medio ambiente propicio para influir sobre la higiene, el espíritu y el buen gusto» y favorecer en los jóvenes una conciencia de sí a la vez que «una educación cívica mejor entendida y más conforme con una democracia en marcha hacia destinos grandiosos».43 Esta oficina, a pesar de su provisorio local, respondía «inmediatamente á la realización del programa de educación estética en las escuelas primarias» siendo su función «reproducir ilustraciones, vistas, paisajes, retratos de prohombres, de cuadros célebres» con el fin de aprovisionar a todas las escuelas bajo la égida del Consejo Nacional de Educación. ${ }^{44}$

\footnotetext{
40 «Notas de la Redacción» El Monitor de la Educación Común 28, no. 435 (31 de marzo, 1909): 571.

${ }^{41}$ Carlos Zuberbühler, «El arte en la escuela»; Eduardo Schiaffino, «Educación estética»; Ernesto de la Cárcova, «La educación estética en la escuela», El Monitor de la Educación Común 28, no. 436 (30 de abril, 1909): 3-32. Estos artistas formaron parte de la Generación del 80.

42 «Oficina de ilustraciones y decorado escolar del Consejo Nacional de Educación», El Monitor de la Educación Común 28, no. 436 (30 abril, 1909): 52.

${ }^{43}$ Frumento, «La nueva orientación pedagógica en la enseñanza elemental y secundaria», 322.

44 José M. Ramos Mejía, La escuela argentina en el Centenario. Proyectos del presidente del Consejo Nacional de Educación Dr. José María Ramos Mejía (Buenos Aires: Consejo Nacional de Educación, 1909), 23.
} 
La flamante administración de Ramos Mejía incorporó el empleo de la imagen en el aula y en el entorno escolar. Los debates sobre estas cuestiones no eran en absoluto nuevos. Transformar el aula en un ambiente pedagogizado mediante el recurso de cubrir sus muros con láminas, mapas e ilustraciones, apoyos de la formación estética y moral del niño, ya habían sido valorizados por Sarmiento. ${ }^{45}$ Fue asimismo tema de diversos pedagogos sobre la conveniencia de su uso en la escuela elemental. ${ }^{46}$ No obstante, en esta nueva coyuntura, estos dispositivos visuales adquieren otra significación a la vez que se incrementan. Este incremento se experimenta también en el espacio público callejero como en el entretenimiento popular. Desde las imágenes publicitarias y las vidrieras hasta los espectáculos de vistas ópticas, linternas mágicas e informativas proyecciones luminosas. Estos mismos productos visuales eran reclamados para la enseñanza por su carácter didáctico y persuasivo. Además, el estatuto de estos artefactos apuntaba a ejercitar la observación de lo visible, objetivo tributario del cientificismo coetáneo al igual que la idea de adaptabilidad al medio. Bajo la gravitación de estos discursos, las distintas asignaturas de la escuela común, entre ellas Dibujo, asumirían una función específica en la formación de la nacionalidad, en especial para los niños de variado origen social y cultural. En la escuela y con la contribución del dibujo los jóvenes serían adaptados al medio natural y social a través del desarrollo del «espíritu de observación, atención, reflexión, juicio, razón, iniciativa, disciplina, espíritu de solidaridad, perseverancia», cualidades todas que «entran en juego y abren horizontes en los hombres de ciencia para sus descubrimientos é inventos y en los artistas para sus creaciones». ${ }^{47} \mathrm{Si}$ bien estos aspectos como la acentuación de lo racional, el estímulo a la capacidad de observación y a la disciplina ya se traducían en los objetivos de la materia desde los

\footnotetext{
${ }_{45}$ El concepto de ambiente pedagogizado está tomado de Graciela Augustowsky, «Las paredes del aula. Un estudio del espacio dispuesto por docentes y alumnos», Arte, Individuo y Sociedad 15 (2003):41. https://revistas.ucm.es/index.php/ARIS/article/view/ARIS0303110039B (consultado el 106-2018).

46 Por ejemplo, «Enseñanza objetiva. Ilustraciones», El Monitor de la Educación Común 28, no. 438 (30 de junio, 1909): 577.

${ }_{47}$ Raymundo Robert, «Del dibujo escolar en sus relaciones con las aptitudes del niño», El Monitor de la Educación Común 25, no. 392 (30 de septiembre, 1905): 169-170.
} 
ochenta, en este nuevo marco fueron resignificados junto con la reformulación de algunos de sus contenidos.

\section{DIBUJO ENTRE LA CUESTIÓN NACIONAL Y EL TRABAJO PROFESIONAL; ENTRE LA ESTÉTICA Y EL HIGIENISMO}

Para comprender la significación de las iniciativas sobre educación artística en el período inmediatamente posterior a la gestión de Malharro, es preciso situarlas dentro de una discusión pública más amplia. En este marco, la cuestión social y el estímulo del sentimiento patrio se asociaron al viejo debate sobre la formación profesional, al pensamiento higienista y a la lucha contra el anarquismo en los lustros previos al Primer Centenario. Eran tiempos de fuerte conflicto político y revuelta social. Las rencillas dentro del oficialismo, la situación militar y el accionar del radicalismo en pleno proceso de reorganización, más las huelgas y otras movilizaciones de trabajadores caracterizaron la administración de Manuel Quintana. ${ }^{48}$ En torno al Centenario, los conflictos y protestas obreras se agudizaron, circulando entre la élite dirigente la imagen del inmigrante desagradecido, de cuño anarquista, que «recibido aquí con la hospitalidad y cordialidad que nos distingue, se había propuesto descomponernos nuestra fiesta, transformándola en una de sangre». ${ }^{49} \mathrm{La}$ fiesta referida eran las celebraciones centenarias.

La cuestión social era nacional, donde la semblanza del subversivo del orden podía hacer peligrar el sentir por la nación. De allí que «el amor y el conocimiento de la patria son los mejores frenos para los impulsos egoístas y antisociales de los ciudadanos». Se entendía que «el sentimiento, la idea y la acción de la solidaridad colectiva en el trabajo y la producción del individuo» constituían un tópico desatendido por los

\footnotetext{
${ }^{48}$ La Unión Cívica Radical (UCR) recuperaba concepciones revolucionarias decimonónicas, al incentivar la violencia para enfrentar al gobierno. Concepciones combatidas por el Partido Autonomista Nacional (PAN) desde 1880, por ser prácticas asociadas a la barbarie, atraso y desorden perjudiciales para el país. Luego de la rebelión cívico-militar de 1905, se encararon reformas para garantizar la vuelta al orden.

49 Ángel Carrasco, Lo que yo vi desde el 80... Hombres y episodios de la transformación nacional (Buenos Aires: P.B.O.C.M.O., 1947) citado en Osvaldo Pellettieri Testimonios culturales argentinos: la década del 10 (Buenos Aires: Belgrano, 1980), 19.
} 
anarquistas o por aquellos políticos o ciudadanos que «creyéndose conservadores, suelen proceder como verdaderos anarquistas». ${ }^{50}$ La solidaridad y la disciplina social se presentaron como uno de los problemas de urgente resolución desde la educación. Este fue el objetivo central de la gestión de Ramos Mejía. Redefinió así el rol del Consejo Nacional que debía «tomar una participación principal en la celebración del Centenario de la Revolución de Mayo, porque es el encargado de orientar el pensamiento de la escuela y porque ésta representa el germen del alma nacional». ${ }^{51}$ En esta dirección, rediseñó la materia Dibujo de forma que favoreciera la gestación de sentimientos patrios homogeneizadores, la veneración de los símbolos nacionales, sus tradiciones y figuras heroicas bajo la gravitación de la idea de solidaridad. En las conferencias pedagógicas que proyectó Ramos Mejía se planearon temas y propósitos generales atinentes al arte y a la estética en el conjunto del cotidiano escolar, y específicos referidos a la asignatura y sus contenidos. En este sentido, como primer punto del temario de las conferencias, se proponía atender la adaptación de la escuela primaria a las exigencias de la cultura estética, así como «crear en la escuela un medio favorable al desarrollo del gusto artístico». Este último aspecto abarcaba las características del edificio escolar, el decorado, las ilustraciones empleadas en el aula, el material de enseñanza, libros y cuadernos. ${ }^{52}$

Con el alejamiento de Malharro operaron efectivamente otros lineamientos en la enseñanza de la materia Dibujo que acompañaron las nuevas disposiciones dentro de la política educativa de lo nacional. Las estrategias inaugurales, fundadas en las nuevas corrientes pedagógicas y científicas, introdujeron un recorte en los contenidos de la asignatura, del programa de capacitación docente en la materia instaurado años antes y una ampliación de lo estético en el ámbito escolar: «veinte años atrás, hablar de educación estética en la Escuela Primaria, era un atrevimiento que colocaba al que tal hacía en el grupo de los que ambicionan

\footnotetext{
50 Carlos Bunge, «La educación y la disciplina social», El Monitor de la Educación Común 33, no. 449 (31 de mayo, 1910): 338 .

51 Ramos Mejía, La Escuela Argentina en el Centenario, 3.

52 Ramos Mejía, La Escuela Argentina en el Centenario, 29-30.
} 
salir de la vulgaridad á todo trance, utilizando medios violentos y paradójicos. Hoy día, la situación ha cambiado». ${ }^{53}$ Sin duda, se iniciaba el interés por la formación estética, pero se recortaban logros previos. Los cursos normales teórico-prácticos de dibujo para maestros establecidos por Pizzurno, procuraban una mejora en la enseñanza, mediante la investigación y el estudio «de puntos que hasta ahora se habían considerado poco menos que inútiles para el buen desarrollo de la asignatura». Empero, bajo Ramos Mejía fueron suspendidos el 20 de abril de 1909. Se esgrimió como justificativo que en las escuelas elementales se debían enseñar saberes comunes en lugar de saberes especiales o profesionales. De este modo, toda maestra normal se hallaba en condiciones de enseñar la asignatura Dibujo sin la necesidad de recurrir a una capacitación extra. Se aseguraba que continuar con esos cursos implicaría desconocer la obra de las escuelas normales formadoras de maestros y recargar la tarea de los docentes «á quienes, por otra parte, se les descalifica dándoles patente de inservibles». Se sostuvo que la especialización estaba destinada a la formación en escuelas superiores o técnicas, pues la escuela primaria no se proponía formar «carpinteros, dibujantes ó pintores, porque no es escuela técnica ó profesional». ${ }^{54}$ Se avivaban así las discusiones sobre el utilitarismo en la materia.

Este pensamiento entraba en contradicción con lo formulado a fines del siglo anterior y con lo actuado cuatro años antes. El problema era que, de acuerdo a la estadística, la gran mayoría de los niños abandonaba la primaria al concluir el cuarto grado para dedicarse al trabajo profesional. En la década del noventa se postuló como posible solución que el dibujo geométrico se ubicara en los grados inferiores, desde el primer grado, junto con el «Dibujo de objetos», «Colorido»y «Aplicaciones» que abarcaba el dibujo de accidentes geográficos, planos sencillos, itinerarios y empleo en el trabajo manual. ${ }^{55}$ Pesaba por entonces el convencimiento de su contribución «á la educación profesional del niño: es

\footnotetext{
53 Clotilde Guillén, «Educación estética», El Monitor de la Educación Común 31, no. 489 (30 de abril, 1913): 48.

${ }^{54}$ Ernesto Bavio, «Dictámenes», El Monitor de la Educación Común 28, no. 436 (30 de abril, 1909): 460-462.

55 «Los programas», El Monitor de la Educación Común 17, no. 283 (31 de enero, 1897): 111.
} 
imposible citar una sola carrera donde el dibujo no tenga alguna aplicación, siendo en todas ó casi todas, indispensable».56 Cabe recordar que en 1901 se reunieron Dibujo y Geometría en una única materia. ${ }^{57} \mathrm{Se}$ sostenía la conveniencia de introducir mayor cantidad de saberes en los primeros años para compensar la deserción escolar.

Por el contrario, en una conferencia de 1905 se apuntó que, desde el cuarto grado, el dibujo escolar debía entrar en relaciones con el dibujo profesional como atractivo para evitar el abandono escolar. ${ }^{58}$ Por consiguiente, al destinar el dibujo orientado a las profesiones y oficios en los grados superiores, se ambicionaba desalentar la deserción, al ofrecer en los últimos años una formación más completa.

En suma, se tratase de un caso o del otro, del dibujo profesional en los grados inferiores o en los superiores, ambas posturas consideraron a la asignatura Dibujo en la primaria como preparación básica para los oficios o la faena de futuros obreros. La reacción de Bavio fue eliminar todo lo relativo a la capacitación práctica a fin de incentivar la impregnación visual de lo nacional.

La otra dimensión señalada refiere a la educación integral. Ramos Mejía respondía a un ideal grecolatino donde el individuo para devenir en ciudadano debía fundar su formación en la unión armoniosa de fuerza física, moral, estética e intelectual, y «el sentimiento estético debe cultivarse y desarrollarse en todos los ciudadanos y no ser el patrimonio de una minoría adinerada».59

Es interesante señalar que la estética, aparte de ser percibida como un aporte al desarrollo del pensamiento crítico y reflexivo, permitiría «colmar el vacío dejado en la escuela por la supresión de la enseñanza religiosa, en cuanto suscita emociones análogas y sugiere impulsos

\footnotetext{
56 «Enseñanza del dibujo. Instrucciones para los maestros de las escuelas primarias», El Monitor de la Educación Común 18, no. 305, (31 de agosto, 1898): 193.

57 «Los nuevos programas», El Monitor de la Educación Común 18, no. 344 (31 de octubre 1901): 193-194.

58 Salas y Troller, «El dibujo en la escuela primaria», 1040-1045.

59 Frumento, «La nueva orientación pedagógica en la enseñanza elemental y secundaria», 317.
} 
generosos y humanitarios». ${ }^{60}$ La transformación educativa de la mano del positivismo reemplazó la enseñanza de la moral religiosa por la moral cívica. La solidaridad que implicaba su enseñanza, que en la vida nacional concernía al Estado, suponía además una preparación para la vida práctica. La educación moral era infundida también a través de lo sensible «y más aun en una sociedad como la nuestra en que debe desarrollarse la moralidad á medida que aumenta la libertad».61 Formar al niño en un entorno estético favorecería la transmisión de una cultura moral y el desenvolvimiento de una sociedad armoniosa y ordenada, exenta de conflictos.

Para algunos coetáneos la enseñanza del arte comportaba «el control por parte del docente de posturas, actitudes y comportamientos del niño». En este sentido, el equilibrio y «la armónica relación entre esas facultades, deben constituir el ideal estético de la escuela» para la realización del mejoramiento intelectual y moral del individuo. ${ }^{62}$ Estos aspectos se insertaban en la escuela como factores concurrentes a la formación moral y cívica del niño por medio del aprendizaje en Dibujo. En otras palabras, esta materia contribuía a este tipo de enseñanza, suministrando racionalmente predisposiciones y comportamientos. También lo hacía adicionando una dimensión visual, al introducir a los jóvenes en hábitos de observación, una observación dirigida y controlada, y al incentivar el uso de determinadas imágenes que respondían a un repertorio patrio específico: símbolos y figuras heroicas, tradiciones, episodios históricos y paisajes típicos. Esta iconografía además era enseñada con ejercicios de copia, representaciones repetitivas que se adecuaban a la misma metodología aplicada en otras materias, especialmente Historia. Se trataba de un aprendizaje basado en la articulación de relatos fundacionales, efemérides y figuraciones patrias, que apelaban a la afectividad y emoción para la construcción de lazos de identificación y pertenencia,

\footnotetext{
${ }^{60}$ Frumento, «La nueva orientación pedagógica en la enseñanza elemental y secundaria», 323.

${ }^{61}$ María Rosa Fusco, "Cultura moral», El Monitor de la Educación Común 29, no. 445 (31 de enero, 1910): 75.

${ }^{62}$ Fernando Fusoni, «El arte en la escuela», El Monitor de la Educación Común 30, no. 472 (30 de abril, 1912): 30 .
} 
eliminando el conflicto y la diferencia. ${ }^{63}$ De esta manera, la materia Dibujo aportaba a la configuración de una trama de relatos visuales por medio de retratos, íconos y símbolos patrios. Al lado de Dibujo, el uso didáctico de la imagen, las salidas escolares, las revistas ilustradas, la decoración móvil y la organización arquitectónica, fueron otros tantos medios para propiciar la educación estética y patriótica.

A ello se asoció el higienismo ${ }^{64}$, como beneficioso para el escolar, puesto que «después de batallar por la higiene de las escuelas, dotándolas de condiciones de salubridad, se ha caído en la cuenta de que no es suficiente que no sean dañosas á los tiernos organismos infantiles, sino que es necesario, además, que no depriman el espíritu», y coadyuven al mantenimiento de la atención. ${ }^{65}$ La cuestión relativa a la nacionalidad se entretejía con el problema de la atención del niño y la educación del gusto estético. ${ }^{66}$ Para Ramos Mejía se tornaba posible administrar y moldear la masa urbana para la construcción de la nación a través de la instrucción elemental y de la creación de un entorno adecuado. Y en esta tarea se amalgamaban el gusto estético y la salubridad.

En lo que atañe a sus funciones médicas, impulsado por los nuevos saberes del higienismo francés y los aportes del pensamiento bacteriológico, Ramos Mejía encaminó reformas que incidieron en el ámbito escolar y, por consiguiente, en lo atinente a Dibujo. Se propició la introducción de reformas en los espacios escolares, en los hábitos y conocimientos disciplinares, «según las exigencias de la higiene y la estética urbana, subordinando á igual criterio de salud y de buen gusto la distribución de las

\footnotetext{
${ }^{63}$ Por ejemplo, sobre la asignatura historia, Mario Carretero y James Voss, Aprender y pensar la historia (Buenos Aires: Amorrortu, 2004).

${ }^{64}$ El higienismo fue una corriente desarrollada a fines del siglo dieciocho impulsada por las preocupaciones con respecto al entorno, el hábitat y la salubridad, centrada en la lucha por la erradicación de enfermedades, especialmente en el ámbito urbano y que afectaban mayormente a los sectores populares de la población. Para ampliar Alejandro Khol, Higienismo argentino. Historia de una utopia. La salud en el imaginario colectivo de una época (Buenos Aires: Editorial Dunken, 2006).

${ }_{65}$ Manuel Rodríguez Codolá, «El arte en la enseñanza primaria», El Monitor de la Educación Común 29, no. 445 (31 de enero, 1910): 838-846.

${ }^{66}$ Carlos Martinelli, «El dibujo y los maestros», El Monitor de la Educación Común 33, no. 508 (30 de abril, 1915): 628.
} 
aulas y su decorado». ${ }^{67}$ Un aspecto de la escuela en tanto cuestión social fue la terminación de los estudios primarios a una edad que coincidiera con el deseado límite higiénico para el trabajo obrero. ${ }^{68}$ Es de interés esta apreciación si se tiene en consideración que este límite, aunque despojado de vertientes higienistas, fue asimismo límite de contenidos en la asignatura relativos a su función utilitaria.

La tendencia utilitaria continuó generando pugnas en lo que respecta a su inclusión en los planes de la escuela elemental. Aparte de algunas declaraciones de Ramos Mejía que objetaban esta tendencia y de las propias de Malharro, para quien las prácticas e ideales del dibujo de tipo industrial tenían poco radio de acción en la primaria, permanecían voces a su favor. No obstante, la enseñanza aplicada se fragmenta y extiende. La creación de escuelas de artes y oficios, como estudios posteriores de especialización, se hicieron cargo de su demanda. En la primaria fue la introducción de la materia Trabajo Manual el curso que canalizó las expectativas referentes a la formación laboral, implementado en 1889 a modo de ensayo en algunas escuelas capitalinas e incorporado oficialmente en 1896 de primero a sexto grados. Esta incorporación fue bienvenida especialmente por los sectores docentes normalistas que hacía tiempo venían reclamando su inclusión, y por las propuestas que pregonaban integrar ambas materias. Además de ser vista como un progreso pedagógico, se presumía que la enseñanza manual «regenerará nuestra sociedad: sus efectos se harán sentir en el futuro, por mejor constitución física en el pueblo, mas espíritu de observación, amor al trabajo y aptitud para las artes».69 Se trataba de la arista práctica y aplicativa de las técnicas de dibujo como materia, mientras que la asignatura Dibujo reformulaba sus objetivos y temario.

En los tiempos previos a la gestión de Ramos Mejía e incluso durante sus primeros meses, había existido dentro de la estructura oficialista

\footnotetext{
${ }^{67}$ Carlos Zuberbühler, «El arte en la escuela», El Monitor de la Educación Común 28, no. 436 (30 de abril, 1909): 3.

${ }^{68}$ Leopoldo Lugones, «Didáctica», El Monitor de la Educación Común 29, no. 448 (30 de abril, 1910): 49. 69 «Posibilidad del Trabajo Manual», El Monitor de la Educación Común 13, no. 246 (31 de marzo, 1894): 780 .
} 
cierto margen para la formulación de estrategias diferenciadas, como lo fue el accionar de Malharro al mando de la inspección de Dibujo. El endurecimiento de la empresa patria fue tomando cuerpo cuando a la administración de Ramos Mejía se sumó Bavio, ferviente impulsor de una homogenización cultural a ultranza. Consecuentemente, en la materia Dibujo se procuró el establecimiento de correlaciones entre sus lecciones y la enseñanza de la historia nacional, a la par que se las adaptaba a la búsqueda de la libertad de expresión del niño, pero en un sentido diverso al pretendido por Malharro. A modo ilustrativo, Malharro exigía que en la práctica del dibujo libre los niños presentaran con frecuencia «temas de carácter nuestro» mediante la expresión de sus propios sentimientos y su propia óptica estética sobre la historia nacional. ${ }^{70}$ En cambio, durante los años duros de Bavio, se ordenaba que los niños reprodujeran meramente iconografías. El dibujo libre y del natural, tan valorados por Malharro, se restringieron a «trazar la bandera argentina, el escudo nacional, el antiguo Cabildo, plano antiguo de Buenos Aires, pirámide de Mayo, alegorías de la Patria y de la Libertad, soldados de aquella época, buques de la escuadrilla patriótica» y en los grados más avanzados «estátuas y monumentos históricos, y hasta retratos de prohombres argentinos». Sin embargo, Bavio no dejó de acotar: «es claro que se trata de dibujos libres». ${ }^{71}$ Una comprensión particular del dibujo libre.

\section{IDEAS FINALES}

En un renovado contexto curricular la materia ganó nuevos enlaces con objetivos utilitarios que apuntaban a la formación de individuos con aptitudes profesionales para la sociedad moderna. Sin embargo, esta reorientación pronto concluyó. Aún más, la intervención de Ramos Mejía y Bavio implicó mucho más que una reestructuración del programa de la materia Dibujo. Propició un corte con lo realizado hasta el momento y avivó polémicas y luchas de poder que condujeron a un reacondicionamiento de su enseñanza a modos más tradicionales.

\footnotetext{
70 Pizzurno, «La educación patriótica», 350-351.

71 Ernesto Bavio, «Instrucciones sobre la Semana de Mayo: á los directores y maestros», El Monitor de la Educación Común 28, no. 437 (31 de mayo, 1909): 327.
} 
A partir de 1910 Ramos Mejía aprobó una nueva planificación con carácter provisional. En 1914 el programa continuó prácticamente en los mismos términos, con la aclaración de que no se trataba de un plan definitivo. ${ }^{72}$ Era evidente que el espíritu inyectado por Malharro a la enseñanza del dibujo se había desvanecido. Hubo un corrimiento de la significación del dibujo libre, dejando paso a la gravitación de otra interpretación del pensamiento científico en boga. ${ }^{73} \mathrm{Si}$ uno de los fines de la educación es la preparación para la vida, lema reiterado por los discursos epocales, las materias que componen la currícula deben por consiguiente atender a la supervivencia del sujeto que puede entenderse en un sentido cultural, educativo y social. Así, los procesos políticos, económicos y sociales que tuvieron lugar entre los sectores populares fueron interpretados bajo la óptica del pensamiento de sesgo biológico. ${ }^{74}$

A la orientación centrada en el niño y al arte como lenguaje respondió su propuesta de encaminar Dibujo hacia la enseñanza patriótica. Si bien su diseño estimaba la posibilidad de correlacionar asignaturas, específicamente Historia, Moral y Dibujo, su finalidad disentía de la oficialista enarbolada por Ramos Mejía.

En Malharro los hechos históricos favorecían el incentivo de la imaginación, espontaneidad y sensibilidad del niño. No se trataba de pretender fijar iconografías patrias, de aprehender los rasgos de determinados símbolos nacionales ni de colocar en primer lugar a la versión oficial de la historia local o de arrasar con la diversidad cultural. El niño como individuo y sus propias elecciones y descubrimientos, lejos de la implantación de convencionalismos y disciplina, eran la base de su pensamiento

\footnotetext{
72 «Nuevo plan de estudios y programas», El Monitor de la Educación Común 29, no. 446 (28 de febrero, 1910): 552-559; «Plan de estudios y programas sintéticos y analíticos para las escuelas primarias de la Capital», El Monitor de la Educación Común 29, no. 451 (31 de julio, 1910): 347-359; «Plan de estudios y programas», El Monitor de la Educación Común 32, no. 499 (31 de julio, 1914):154-155.

${ }^{73}$ En este sentido, nuestra postura es coherente con lo sostenido por Artundo, de que en el alejamiento de Malharro intervinieron otras razones aparte de desacuerdos con algunos colegas dentro del campo artístico y educativo. Artundo, «Bibliografía crítica de Martín A. Malharro: el dibujo como agente de educación», 73-108.

${ }^{74}$ Ricardo González Leandri, «Miradas médicas sobre la cuestión social. Buenos Aires a fines del siglo XIX y principios del XX», Revista de Indias 60, no. 419, (2000): 422. doi:http://dx.doi.org/10.3989/ revindias.2000.i219.513.
} 
y gestión. Su accionar no apuntaba tan solo a los fines de la materia sino a la escuela toda. En esta dirección, podría leerse al proyecto de Malharro como una contradicción con respecto a la idea de nación como entidad totalmente homogénea y al entendimiento limitado de la disciplina conductual, como lo hacía el oficialismo. La intención de Malharro no suponía indiferencia a lo nacional o a los valores patrios sino otro modo de encararlos. Frente a su incentivo al niño como individuo creativo libre y la apertura a la experimentación, la propuesta de Ramos Mejía pretendía la amalgama de los individuos en un colectivo coherente, la nación. Tampoco significó la arremetida de Ramos Mejía la prohibición de libertades, creatividad e imaginación, pero se atendía a otros principios como modelos futuros. En consecuencia, el posicionamiento de Malharro frente a la cuestión nacional era crítico de la homogeneización cultural, de la imposición de conductas y de la misma función que se le había asignado a la escuela.

Luego del distanciamiento de Malharro, Ramos Mejía encaminó la materia como una pieza más de un mecanismo, la escuela, atravesado por lo estético y el arte. Acentuó el uso de la imagen en todas sus formas, teniendo en cuenta las tecnologías de la época. Así fue, tanto en la propia materia Dibujo como en otras asignaturas y en el ambiente escolar, la arquitectura y la organización del salón, en especial a medida que se aproximaban los festejos de los dos Centenarios. Ramos Mejía representaba además una vertiente nacionalista asociada al nuevo perfil médico finisecular. Al igual que el enlace entre la cuestión social y la cuestión nacional, la educación fue abrazada por las políticas higienistas. En este punto el interrogante que surge es cómo empalma este incentivo a lo estético con el higienismo en la escuela. En el contexto de las transformaciones sociales de fin de siglo, las ideas higienistas se extendieron hacia el saneamiento y regeneración de la población. En lo cultural, la higiene era portadora de los valores de la civilización, de sus pautas de comportamiento, entre ellas, formar el buen gusto artístico en el grueso de la población. Este último aspecto fue asimismo bandera de la elite de artistas del campo artístico porteño, entre ellos Eduardo Schiaffino, quien apoyó la campaña de Ramos Mejía. La irregularidad, los excesos y la diversidad se asociaban al mal gusto, del mismo modo que la diversidad 
cultural o los excesos y vicios en los hábitos de vida, eran las malas costumbres de los sectores populares que el programa higienista debía sanear. A su vez, a la multitud vil librada a sus pasiones, que podrían estar lindantes con las ideologías extremas, oponía una ciudadanía responsable producto de la escolarización en un ambiente saludable y confortable. La formación moral y cívica proporcionada por el conjunto de disciplinas básicas de la primaria, entre las que se hallaba Dibujo, pretendió reforzar la tradición patria y los sentimientos nacionales. A la aprehensión de valores nacionales, se adicionaba la solidaridad de clases dentro del colectivo nación como forma de ciudadanía.

Otra referencia significativa es la cuestión del atractivo para el niño. Este rasgo se asoció a despertar el interés, y más allá de ser un problema didáctico, por entonces se presentaba como una causal de la buena conducta, entendida ésta en términos de desalentar espíritus revolucionarios. La modulación de conductas constituía una actividad configuradora de la ciudadanía moderna. A ello no fue ajena Dibujo que, de acuerdo a los parámetros de su programación, aportó la exigencia postural, la adecuación a circunstancias regladas y convencionales, el observar con precisión, copiar o imitar diseños preseleccionados y la unificación de los distintos patrones de comportamiento acarreados por la pléyade inmigrante en el ámbito escolar.

\section{Nota sobre la autora}

Patricia andREa Dosio es Licenciada y Profesora en Artes, graduada con Diploma de Honor por la Universidad de Buenos Aires (UBA). Doctora en Historia (Universidad Torcuato Di Tella), con posgrados en Educación (Facultad Latinoamericana de Ciencias Sociales-FLACSO). Se ha desempeñado como docente de Didáctica de Artes y Prácticas de la Enseñanza de la carrera de Artes en la Universidad de Buenos Aires, en la Universidad Nacional de Tres de Febrero y en el Área de Investigación y Producción de la Facultad de Diseño y Comunicación de la Universidad de Palermo (Buenos Aires). Ha publicado numerosos estudios e investigaciones especialmente sobre arte argentino y enseñanza del dibujo durante el siglo diecinueve. 


\section{REFERENCIAS}

Artundo, Patricia. «Bibliografía crítica de Martín A. Malharro: el dibujo como agente de educación». Boletín del Instituto de Teoría e Historia del Arte Julio E. Payró 9 (2003): 73-108.

Augustowsky, Graciela. «Las paredes del aula. Un estudio del espacio dispuesto por docentes y alumnos/as en la escuela primaria». Arte, Individuo y Sociedad 15 (2003): 39-59. https://revistas.ucm.es/index.php/ARIS/article/view/ ARIS0303110039B.

Bottarini, Ricardo. «Leer, escribir, votar: la conflictiva definición del curriculum ciudadano». En Para una historia de la enseñanza de la lectura y la escritura en la Argentina: del catecismo colonial a La Razón de Mi Vida. Dirigido por Héctor Cucuzza y Pablo Pineau, 77-105. Buenos Aires: Miño y Dávila Editores, 2002.

Carli, Sandra. Niños, pedagogía y política. Transformaciones de los discursos acerca de la infancia en la historia de la educación argentina entre 1880 y 1955. Buenos Aires: Universidad de Buenos Aires/Miño y Dávila, 2002.

Carretero, Mario y James Voss. Aprender y pensar la historia. Buenos Aires: Amorrortu, 2004.

Dosio, Patricia Andrea. «Aprender a dibujar los contornos del país: Vínculos entre la enseñanza del dibujo escolar y los conocimientos geográficos en el Buenos Aires finisecular (1880-1900)». Caderno de Geografia 24, no. 2 (2014): 90-104. https://www.aacademica.org/patricia.andrea.dosio/9.

Dosio, Patricia Andrea. «Entre el atelier, la escuela y la fábrica: La Sociedad Estímulo de Bellas Artes y la capacitación de mano de obra urbana en el Buenos Aires decimonónico». Reflexión Académica en Diseño y Comunicación 25, no. 23 (2014), 93-99.

González Leandri, Ricardo. «Miradas médicas sobre la cuestión social. Buenos Aires a fines del siglo XIX y principios del XX». Revista de Indias 60, no. 419 (2000): 421-435. doi:http://dx.doi.org/10.3989/revindias.2000.i219.513.

Halperin Donghi, Tulio. El espejo de la historia. Problemas argentinos y perspectivas latinoamericanas. Buenos Aires: Sudamericana, 1987.

Khol, Alejandro. Higienismo argentino. Historia de una utopía. La salud en el imaginario colectivo de una época. Buenos Aires: Editorial Dunken, 2006.

Lertora Mendoza, Celina. «Recepción de ideas filosóficas. Problemas metodológicos e histórico-críticos de su investigación. Estudio de caso: la filosofía argentina de 1890 a 1920». Cuadernos del Sur 31-32 (2001): 37-63. http://bibliotecadigital.uns.edu.ar/scielo.php?script=sci_arttext\&pi$\mathrm{d}=\mathrm{S} 1668-74342001001100003$

Pellettieri, Osvaldo. Testimonios culturales argentinos: la década del 10. Buenos Aires: Belgrano, 1980. 
Puiggrós, Adriana y Sandra Carli. Sociedad civil y estado en los orígenes del sistema educativo argentino. Buenos Aires: Galerna, 1991.

Puiggrós, Adriana y Rafael Gagliano. La fábrica del conocimiento: los saberes socialmente productivos en América Latina. Rosario: Homo Sapiens, 2004.

Vallejo, Gustavo y Marisa Miranda. «Evolución y revolución: explicaciones biológicas de utopías sociales». En El pensamiento alternativo en la Argentina del siglo XX, dirigida por Hugo E. Biagini y Arturo A. Roig, 403-417. Buenos Aires: Biblos, 2004. 